Cahiers d'études africaines

Goerg, Odile (coord.). - Perspectives historiques sur le genre en Afrique

Paris, Groupe Afrique, Laboratoire SEDET/CNRS, Université Diderot-Paris 7, Cahier $n^{\circ} 23,2007,285$ p.

Françoise Raison-Jourde

\title{
OpenEdition
}

Journals

Édition électronique

URL : http://journals.openedition.org/etudesafricaines/9332

DOI : 10.4000/etudesafricaines.9332

ISSN : $1777-5353$

Éditeur

Éditions de l'EHESS

Édition imprimée

Date de publication : 15 décembre 2007

Pagination : 783-784

ISBN : 978-2-7132-2140-8

ISSN : 0008-0055

Référence électronique

Françoise Raison-Jourde, "Goerg, Odile (coord.). - Perspectives historiques sur le genre en Afrique », Cahiers d'études africaines [En ligne], 187-188|2007, mis en ligne le 11 janvier 2008, consulté le 24 septembre 2020. URL : http://journals.openedition.org/etudesafricaines/9332 ; DOI : https://doi.org/ 10.4000/etudesafricaines.9332

Ce document a été généré automatiquement le 24 septembre 2020.

(C) Cahiers d'Études africaines 


\section{Goerg, Odile (coord.). - Perspectives historiques sur le genre en Afrique}

Paris, Groupe Afrique, Laboratoire SEDET/CNRS, Université Diderot-Paris 7, Cahier $\mathrm{n}^{\circ} 23,2007,285 \mathrm{p}$.

\section{Françoise Raison-Jourde}

1 Le cahier que le groupe Afrique du laboratoire SEDET consacre au genre est précédé d'une riche introduction de 0 . Goerg.

2 En m'excusant d'avance pour une mise en lumière fatalement inégale des travaux, je distinguerai deux approches, celle d'Histoire des femmes, désormais classique, et celle relevant du Genre, qui s'attache aux rapports sociaux entre sexes, à la relation des hommes et femmes au corps, à la construction des identités masculines ou féminines. Les travaux les plus neufs s'attachent au passage de frontières que le savoir académique érige en termes trop dichotomiques : blancs/colonisés, privé/public, politique/social.

3 Frontière raciale et transgression sexuelle: Amandine Lauro suit le changement d'attitude accompagnant le passage de l'État du Congo au statut de colonie belge en 1909. Les couples incluant une femme africaine sont autant de «transgressions insupportables» annonçant décivilisation et négrification, perte d'autorité des dominants. Le clergé s'associe aux autorités civiles pour dénoncer le détournement de jeunes filles chrétiennes sans doute trop bien formées à la tenue d'un intérieur par les religieuses. Le chapitre suivant note en AOF combien les Blancs venus en célibataires jouissent de leurs « aventures » en brousse, de l'affranchissement des « contraintes de familles bourgeoises ». L'installation de l'Entre-deux-guerres fait passer à la colonie " en bigoudis » (selon l'expression d'Albert Londres, 1929). L'après-guerre où arrivent épouses et enfants fait exiger le confort des grands centres et perdre toute intimité avec la vie en brousse. Au Sénégal, avec la création de l'École Normale de filles de Rufisque, en 1938, naît le rêve de couples d'instituteurs «évolués » et monogames, qui va peser surtout sur les visées identitaires féminines: femmes "sérieuses", responsables du foyer et des enfants. Éduquer les filles, suggèrent Pascale Barthélémy et Jean-Hervé Jézéquel, c'est réussir à pénétrer les familles et la sphère privée dans une société largement musulmane. Sur les Hautes Terres malgaches, Violaine Tisseau 
creuse la dissymétrie marquant le sort des enfants métis. Les filles, une fois éduquées, font des épouses potentielles acceptables, voire désirables dans l'intimité des Blancs. Leurs propres enfants se situeront du «bon côté » de la frontière. Les garçons, voués à des tâches souvent spécialisées, relevant de l'espace public, y souffriront de la suspicion du Blanc et épouseront... des Malgaches.

4 La sexualité est donc un lieu stratégique du rapport entre "races » et le corps de la femme africaine cristallise de multiples fantasmes, dont la peur, liée à la puissance supposée de la sexualité africaine. Barrière interraciale aux temps coloniaux, certes, mais n'existe-t-il pas, sur une grande profondeur historique, un souci politique marquant l'espace du pouvoir par une symbolique interdisant elle aussi tout contact sexuel? À la cour du Naaba du Yatenga, le statut des femmes royales est resté longtemps ignoré par des chercheurs portés à l'analyse du pouvoir du côté du masculin. Scarifications, tête rasée, bijoux spécifiques disent une interdiction non verbalisée inscrite dans la peau: captifs et serviteurs sont obligés par leur proximité avec les femmes royales d'adopter tous ces signes apparents de féminisation; ils côtoient des eunuques, qui gardent une apparence masculine mais dont la virilité est anéantie. À lire Marianne Nabaloum, les sociétés coloniales apparaissent quasiment élémentaires dans leur propre tentative de contrôler le sexe dans son rapport au pouvoir!

$5 \mathrm{Au}$ regard de ces corps contraints, c'est la liberté d'invention des étudiantes nigériennes qui étonne E. Nimis. Dans des sociétés musulmanes où les femmes n'ont pas accès au cinéma, elles manient les ressources de l'autoportrait "glamour » et de la vidéo et surtout d'Internet, avec ses forums de discussion sans images, qui s'offrent comme des lieux anonymes, donc libres, de reconstructions identitaires. Dans la banlieue de Dakar, Susann Baller suit une autre reconstruction, celle de leur masculinité, par les jeunes d'une société en crise. Lutte libre et foot permettent la réinvention d'une image de virilité, associée à la figure de héros de la nation ou de la localité.

6 Les quatre dernières contributions concernent le politique et les mutations de rôles accompagnant l'entrée dans l'espace public et sont, en un sens, plus familières. Séverine Awenengo suit les femmes de Casamance dans la constitution d'une conscience joola à partir du statut de mère et des cultes de fertilité propres aux femmes, avec la promotion de cultes déterrorialisés et désexués. Céline Pauthier remonte à l'entrée en politique des Guinéennes au sein du RDA à partir de 1945 : mutation de leurs associations traditionnelles en organes du parti, participation aux grèves et manifestations. Après 1977, le mécanisme se retourne contre le pouvoir, avec les manifestations sur les marchés pour cause de disette.

7 Les Camerounaises se mobilisent dans les ONG (plus de 1000 en 1994), mais les organigrammes de celles qui sont déclarées révèlent une bureaucratisation reproduisant la culture institutionnelle des hommes. Les autres, informelles (85\%), sont peut-être en fait plus vivantes, s'interroge Odile Chatap.

8 L'espace public est enfin lieu d'expérience de la vie dangereuse pour les enfants. Il faut pointer le nouvel esclavage des petites filles, détournement de la pratique ancienne de « confiage » des enfants, ici par des ruraux, à des parents de la ville où elle relève d'une fréquentation scolaire. Fréquentation qui s'accompagne, chez les collégiennes du Togo et du Kenya, de pratiques de prostitution occasionnelle pour assumer les frais de scolarité. 
9 Les quatorze contributions sont étayées par de riches bibliographies qui font de ce numéro un véritable instrument de travail. 